\title{
Impact of a Dedicated Multidisciplinary Research and Treatment Network on Outcomes of Muscle-Invasive Bladder Cancer Patients
}

\section{Debbie G Robbrecht ${ }^{1}$, Rob HA Verhoeven ${ }^{2}$, Peter de Vries ${ }^{3}$, Michiel S van der Heijden ${ }^{4}$, Joost L Boormans ${ }^{5}$ and Ronald de Wit ${ }^{1}$ (on behalf of the Dutch Uro-oncology Study group (DUOS))}

\author{
${ }^{1}$ Department of Medical Oncology, Erasmus University Medical Center, Rotterdam, The Netherlands \\ ${ }^{2}$ Department of Research, Netherlands Comprehensive Cancer Organization, Utrecht, The Netherlands \\ ${ }^{3}$ Department of Urology, Zuyderland Hospital, Heerlen, The Netherlands \\ ${ }^{4}$ Department of Medical Oncology, Netherlands Cancer Institute, Amsterdam, The Netherlands \\ ${ }^{5}$ Department of Urology, Erasmus MC Cancer Institute, Rotterdam, The Netherlands
}

*Corresponding author: Debbie G Robbrecht, MD, Erasmus MC/Cancer Institute, Secretariaat IO NT-5, Postbus 2040, 3000 CA, Rotterdam, The Netherlands, Tel: +31107041505 , Fax +31107041003

\begin{abstract}
Background: The Dutch Uro-Oncology Study Group (DUOS) is a multidisciplinary network of $\sim 30$ hospitals involved in research and treatment of urological cancers. We analyzed the influence of treatment at DUOS versus non-DUOS on survival of muscle-invasive bladder cancer (MIBC) patients and explored correlating parameters.

Patients and methods: Characteristics of 3472 cT24aNO/XMO MIBC patients who underwent radical cystectomy (RC), with or without neoadjuvant chemotherapy (NAC), were collected by the Netherlands Cancer Registry (NCR). 5-year overall survival (OS) was estimated by the Kaplan-Meier method. Cox regression analyses were performed to determine hazard ratios for pre-defined variables.

Results: 5 -year OS differed $3.2 \%$ in favor of DUOS centers ( $49.3 \%$ vs. $46.1 \%, p=0.09)$. Best survival was observed in patients treated with NAC and RC at DUOS centers (5year OS $57 \%$ ). This was $61.1 \%$ in cT3-4 patients treated at DUOS centers. NAC was only significantly associated with improved survival in cT3-4a patients treated at DUOS centers $(p=0.0002)$. Positive surgical margins were less frequent $(p=0.02)$ and more pelvic lymph nodes (LNs) were collected and identified $(p=0.001)$ at DUOS centers. Surgical margins, number of identified LNs, and number of positive LNs significantly correlated with OS.
\end{abstract}

Conclusions: We identified a greater survival benefit by the use of NAC, a higher number of LNs identified, a lower rate of positive surgical margins and a trend towards survival benefit in patients treated at centers that collaborate in the multidisciplinary DUOS national network.
Implications for practice: Our retrospective analysis based on 3472 muscle-invasive bladder cancer patients, showed a non-significant trend towards survival benefit when treated in hospitals involved in a national study-group network (DUOS), with significantly superior outcomes concerning neo-adjuvant chemotherapy, surgical margins and lymph node dissection. These factors significantly correlated with an improved survival, favoring treatment at centers that are involved in a multidisciplinary national network with dedicated care for bladder cancer.

\section{Keywords}

Dedicated center, Muscle-invasive bladder cancer, Retrospective cohort analysis, Survival, Multidisciplinary network

\section{Introduction}

Bladder cancer ranks as the ninth most frequently diagnosed cancer worldwide [1]. In the Netherlands, the annual incidence is $~ 7000$ cases of whom $28 \%$ have muscle-invasive bladder cancer (MIBC) [2]. Variation in the clinical management of MIBC has been reported on an (inter-)national level $[3,4]$ and may impact survival outcomes. In addition, the dedication of multidisciplinary teams in hospitals, which may be consistent with the volume of patients representing MIBC, may play an important role. Dedication to patient care is almost universally associated with the interest to take part in clinical research [5].

Citation: Robbrecht DG, Verhoeven RHA, de Vries P, van der Heijden MS, Boormans JL, et al. (2019) Impact of a Dedicated Multidisciplinary Research and Treatment Network on Outcomes of Muscle-Invasive Bladder Cancer Patients. Int J Cancer Clin Res 6:105. doi.org/10.23937/2378-3419/1410105 Accepted: February 07, 2019; Published: February 09, 2019

Copyright: (c) 2019 Robbrecht DG, et al. This is an open-access article distributed under the terms of the Creative Commons Attribution License, which permits unrestricted use, distribution, and reproduction in any medium, provided the original author and source are credited. 
Since professionals, patients organizations, and health insurances become more and more interested in the potential merits of centralization of cancer treatment, medical societies need to address such questions. Minimum standards in cancer care have been developed by 'SONCOS', a Dutch Cancer Committee in which all medical, paramedical, and nursing disciplines involved in cancer care are represented [6].

In the Netherlands, dedicated centers in the management and research of urological cancers collaborate in the Dutch Uro-Oncology Study Group (DUOS), which represents a foundation of multidisciplinary uro-oncological teams at approximately 30 hospitals. DUOS stands for collaboration, high quality care, participation in and initiation of research, as well as provision of information to health care professionals and patients. DUOS represents all eight academic hospitals, The Netherlands Cancer Institute and a sizeable part of the supraregional hospitals. Participation in recent clinical trials, including pivotal studies with the novel check point inhibitors i.e., was exclusively carried out at DUOS centers [7-9]. In the present study, we retrieved data from the Netherlands Cancer Registry (NCR) [3] with the primary aim to compare clinical outcomes of MIBC patients who underwent $\mathrm{RC}$ with or without NAC at DUOS versus non-DUOS centers. For this purpose we conducted univariate analysis. In case that would reveal outcome differences, we planned to perform multivariable analysis.

\section{Patients and Methods}

We conducted a nationwide, retrospective, population-based study on patients with $\mathrm{CT} 2-4 \mathrm{aNOMO}$ MIBC from the NCR who underwent RC with curative intent between 2005 and 2014 (data including followup data were available for this period). The NCR is a national database in which all newly diagnosed malignancies are registered. Notification is obtained from the registry of histopathology and cytopathology (PALGA) and the National Registry of Hospital Discharge Diagnosis [10]. Independent trained data managers of NCR collected the data on predefined patient, tumor, and treatment characteristics from the patient files in the hospitals. Follow-up on vital status was censored at 31-1-2017. Topography and morphology are classified according to the International Classification of Diseases for Oncology (ICD-O) and tumor stage according to the TNM classification system [11,12].

The population was stratified according to treatment at DUOS versus non-DUOS centers. We defined a medical center as a DUOS center when that center was an actual member of DUOS between 2011 and 2014. To avoid potential bias by low volume surgical procedures, we chose a minimum surgical volume of $10 \mathrm{RC}$ procedures annually, based on the applicable minimum standard Fby SONCOS criteria in 2012-2014 [13]. Centers (DUOS and non-DUOS) that did not fulfill this criterion were excluded from the analyses.
The following pre-defined variables were retrieved; Age, gender, year of diagnosis, NAC, number of identified LNs, number of positive LNs, surgical margins status, tumor grade, pathological (y)pTNM stage, and 30-day postoperative mortality. We chose to define resected LNs being reported by the pathologist, as 'identified LNs' and subdivided the number of identified LNs in ' $1-9$ ', ' $\geq 10$ ' or 'numbers dissected/counted not documented' [14-16]. The primary end point of the study was the 5 -year OS.

\section{Statistical Analyses}

The patient and tumor characteristics were compared by chi-square tests for categorical variables. OS for the entire population and subgroups was analyzed by the Kaplan-Meier method. The difference between the survival curves of the subgroups was tested using the Log-rank. To determine the effect of being treated at a DUOS center on OS, we first performed univariate Cox-regression analysis for the entire cohort and per stage group (cT2 vs. cT3-4a). Thereafter, we added step by step patient characteristics (age, gender, year of diagnosis), NAC and post-operative characteristics (tumor grade, number of identified LNs, number of positive LNs, surgical margins status) to the Cox-regression models to analyze the effect of adjustment for these factors on the effect of being treated at a DUOS center on OS. Due to multicollinearity of NAC and (y)pT stage, we chose to only include NAC into the multivariable Cox regression analyses. Statistical analyses were performed with SAS, version 9.4. P-values $<0.05$ were considered statistically significant (two-sided testing).

\section{Results}

The entire cohort consisted of 3472 patients of whom $82 \%$ had cT2 and $18 \%$ had cT3-4a disease. Most baseline patient and tumor characteristics (Table S1) were equally distributed between DUOS and nonDUOS centers, but the majority of the population ( 2583 patients, 74\%) had been treated at a DUOS center. Median follow-up was 33 months.

There was a modest non-significant difference for the entire cohort in 5-year OS in patients treated at DUOS vs. non-DUOS centers $(49.3 \%(95 \% \mathrm{Cl} 47.3-51.4)$ vs. $46.1 \%(95 \% \mathrm{Cl} 42.6-49.5), p=0.09)$ ) (Figure $1 \mathrm{~A})$. Patients treated with NAC and RC at DUOS centers (n $=242$ ) had the best outcome (5-year OS $57.0 \%(95 \%$ $\mathrm{Cl}$ : 49.5-63.8)), whereas patients not treated at DUOS centers by RC without NAC $(n=809)$ had the worst outcome (5-year OS $45.8 \%$ (95\% Cl: 42.1-49.3)) $(p=$ 0.001) (Figure 1B).

Of all patients, 9.2\% received NAC of whom $40 \%$ had CT3-4a disease. In later years (2011-2014), the frequency of the use of NAC increased to an average of $25 \%$. The association of receiving NAC with survival was only significant in patients treated at DUOS centers 


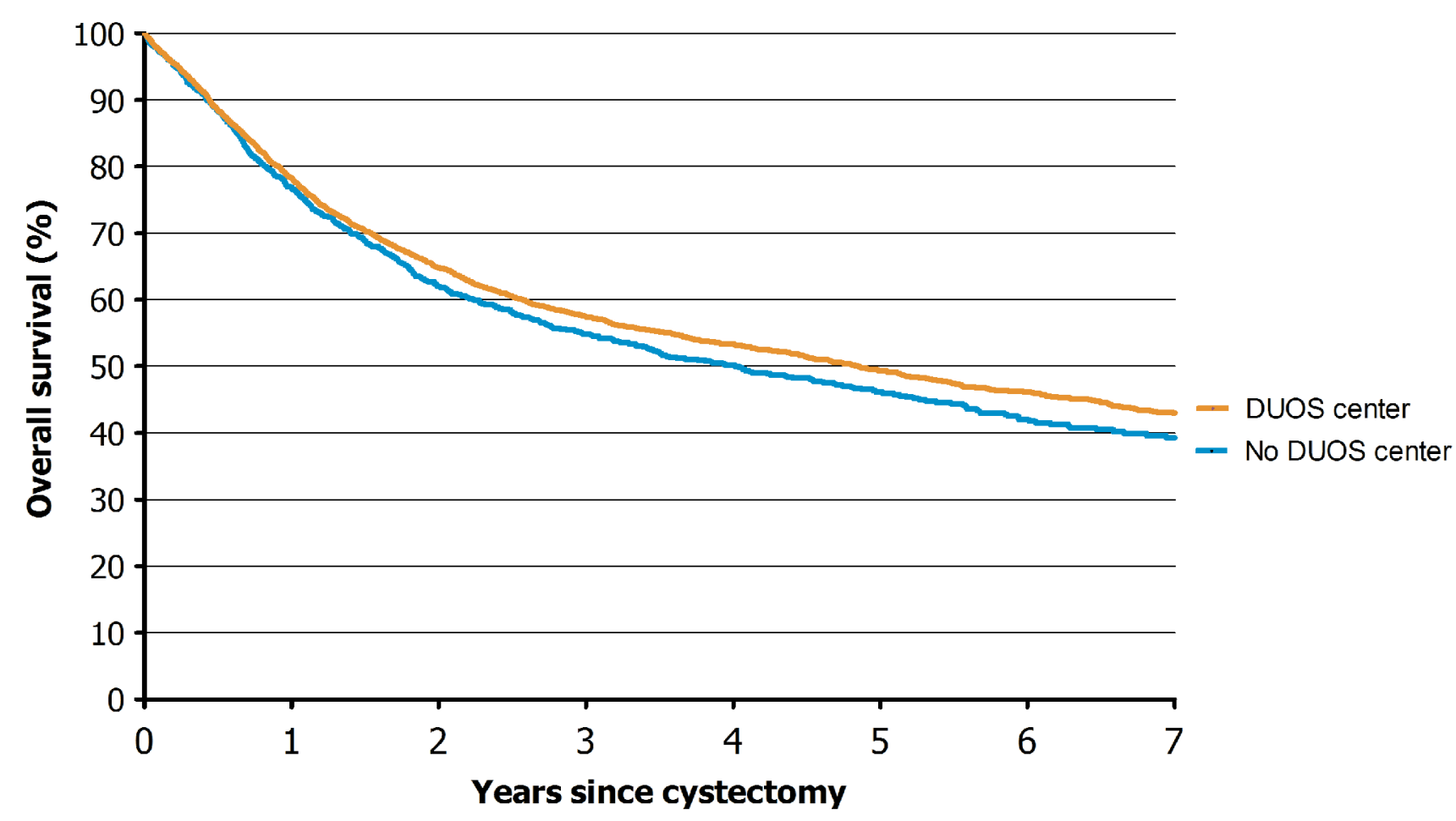

Figure 1A: Overall survival following treatment at DUOS versus non-DUOS centers (total group).

\begin{tabular}{|l|l|l|l|l|l|l|l|l|l|l|}
\hline & $\mathbf{0}$ & $\mathbf{1}$ & $\mathbf{2}$ & $\mathbf{3}$ & $\mathbf{4}$ & $\mathbf{5}$ & $\mathbf{6}$ & $\mathbf{7}$ & $\begin{array}{l}\mathbf{5} \text {-year survival } \\
\mathbf{( 9 5 \%} \mathbf{C l})\end{array}$ & $\begin{array}{l}\text { P-value } \\
\text { DUOS vs. No DUOS }\end{array}$ \\
\hline DUOS center & 2583 & 2013 & 1665 & 1296 & 1031 & 804 & 599 & 445 & $49.3 \%(\mathbf{4 7 . 3}-51.4)$ & 0.09 \\
\hline No DUOS center & 889 & 680 & 549 & 423 & 319 & 253 & 181 & 121 & $46.1 \%(42.6-49.5)$ & \\
\hline
\end{tabular}

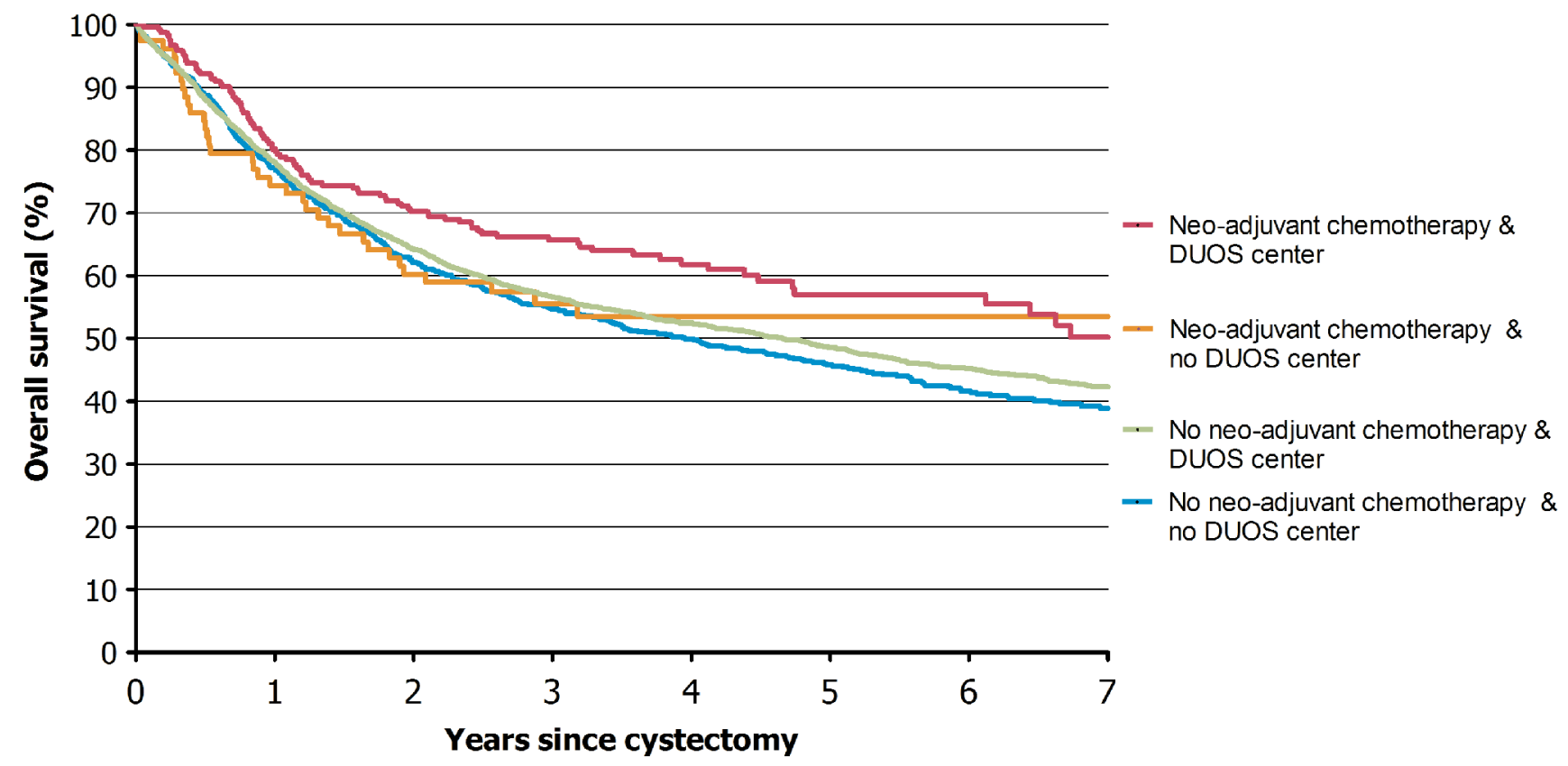

Figure 1B: Overall survival following radical cystectomy with or without neoadjuvant chemotherapy (total group).

\begin{tabular}{|l|l|l|l|l|l|l|l|l|l|l|}
\hline & $\mathbf{0}$ & $\mathbf{1}$ & $\mathbf{2}$ & $\mathbf{3}$ & $\mathbf{4}$ & $\mathbf{5}$ & $\mathbf{6}$ & $\mathbf{7}$ & $\begin{array}{l}\mathbf{5} \text {-year survival } \\
\mathbf{9 5 \%} \mathbf{C l})\end{array}$ & $\begin{array}{l}\text { P-value } \\
\text { NAC vs. No NAC }\end{array}$ \\
\hline NAC \& DUOS center & 242 & 195 & 171 & 121 & 80 & 50 & 39 & 27 & $57.0 \%(49.4-63.8)$ & 0.006 \\
\hline No NAC \& DUOS center & 2334 & 1818 & 1494 & 1174 & 952 & 752 & 560 & 417 & $48.6 \%(46.4-50.7)$ & \\
\hline NAC \& non-DUOS center & 78 & 59 & 48 & 30 & 14 & 8 & 3 & 3 & $53.5 \%(41.4-64.2)$ & 0.699 \\
\hline No NAC \& non-DUOS center & 809 & 621 & 502 & 394 & 305 & 246 & 178 & 119 & $45.8 \%(42.1-49.3)$ &
\end{tabular}




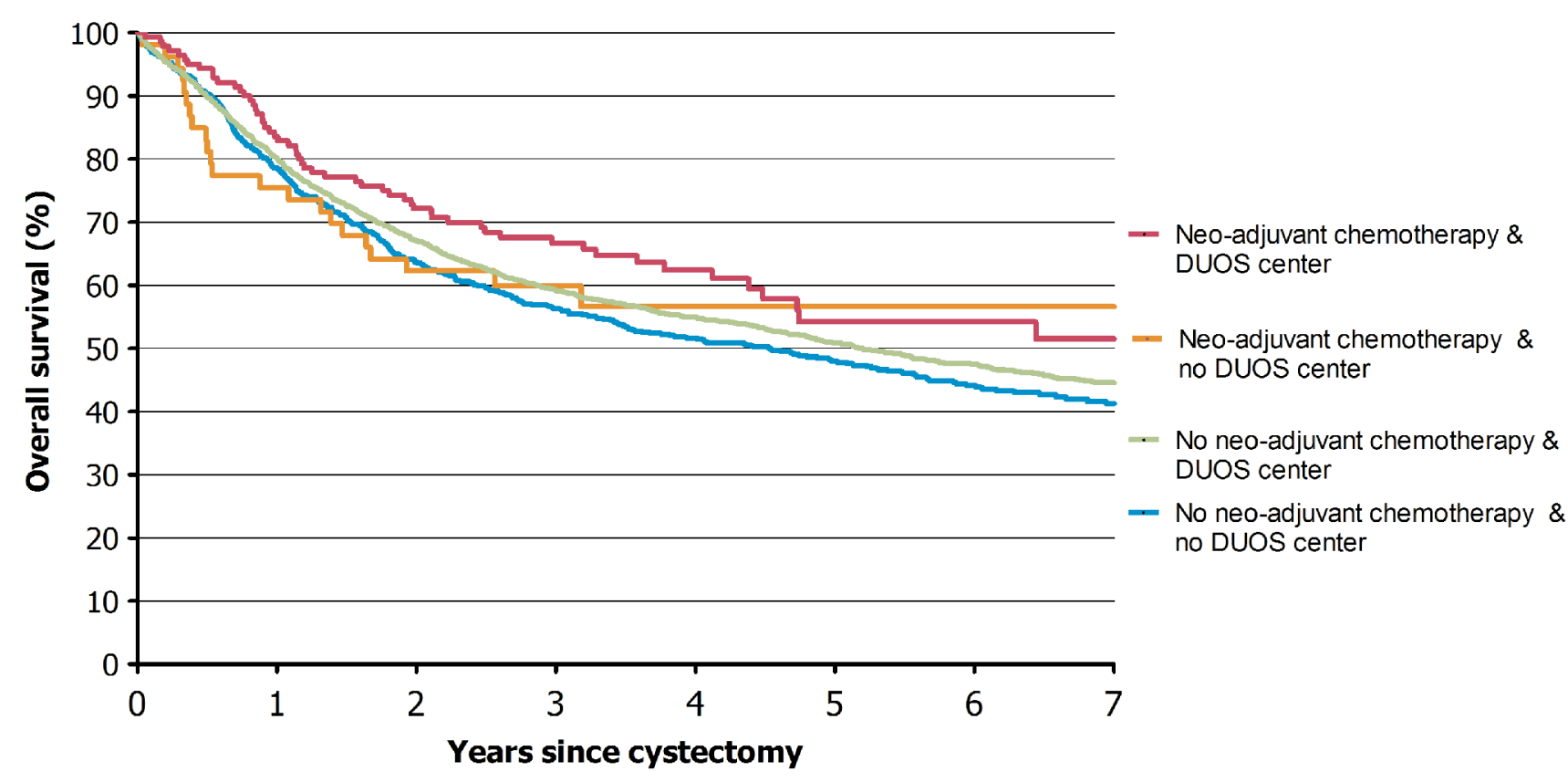

Figure 2A: Overall survival following radical cystectomy with or without neoadjuvant chemotherapy for cT2N0/X patients.

\begin{tabular}{|l|l|l|l|l|l|l|l|l|l|l|}
\hline & $\mathbf{0}$ & $\mathbf{1}$ & $\mathbf{2}$ & $\mathbf{3}$ & $\mathbf{4}$ & $\mathbf{5}$ & $\mathbf{6}$ & $\mathbf{7}$ & $\begin{array}{l}\text { 5-year survival } \\
\text { (95\% Cl) }\end{array}$ & $\begin{array}{l}\text { P-value } \\
\text { NAC vs. } \\
\text { No NAC }\end{array}$ \\
\hline NAC \& DUOS center & 140 & 118 & 102 & 74 & 48 & 27 & 22 & 18 & $54.2(43.8-63.6)$ & 0.08 \\
\hline No NAC \& DUOS center & 1954 & 1562 & 1306 & 1031 & 842 & 665 & 494 & 372 & $50.9(48.5-53.2)$ & \\
\hline NAC \& non-DUOS center & 53 & 41 & 34 & 20 & 9 & 4 & 2 & 2 & $56.6(41.4-69.3)$ & 0.073 \\
\hline No NAC \& non-DUOS center & 696 & 545 & 442 & 352 & 274 & 221 & 163 & 109 & $48.0(44.0-51.8)$ & \\
\hline
\end{tabular}

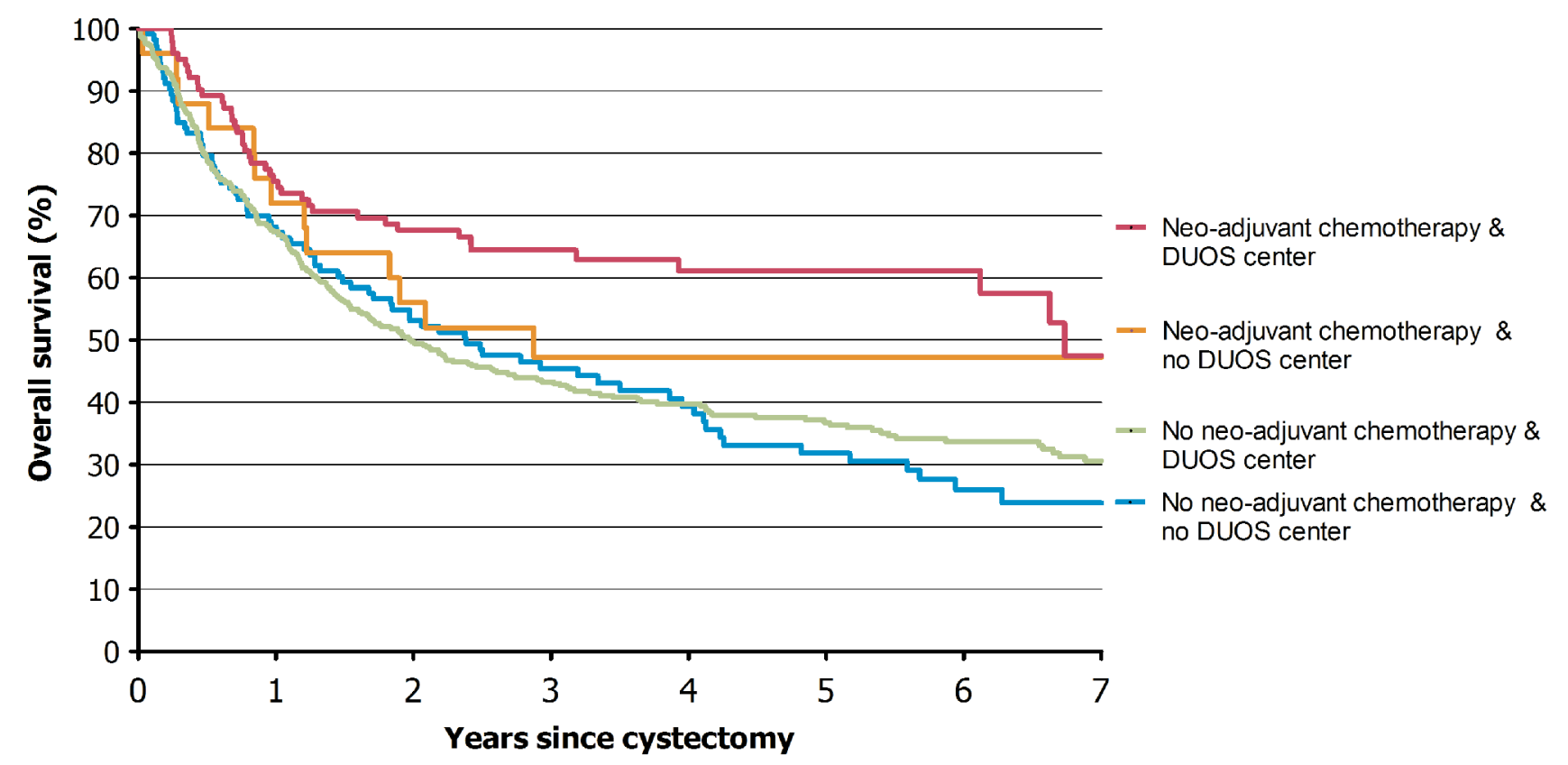

Figure 2B: Overall survival following cystectomy with or without neoadjuvant chemotherapy for cT3/4N0/X patients.

\begin{tabular}{|l|l|l|l|l|l|l|l|l|l|l|}
\hline & $\mathbf{0}$ & $\mathbf{1}$ & $\mathbf{2}$ & $\mathbf{3}$ & $\mathbf{4}$ & $\mathbf{5}$ & $\mathbf{6}$ & $\mathbf{7}$ & $\begin{array}{l}\mathbf{5} \text {-year survival } \\
\mathbf{( 9 5 \%} \text { Cl) }\end{array}$ & $\begin{array}{l}\text { P-value } \\
\text { NAC vs. } \\
\text { No NAC }\end{array}$ \\
\hline NAC \& DUOS center & 102 & 78 & 70 & 48 & 33 & 25 & 18 & 10 & $61.1(50.4-70.2)$ & 0.0002 \\
\hline No NAC \& DUOS center & 380 & 257 & 188 & 145 & 111 & 89 & 67 & 48 & $36.7(31.7-41.8)$ & \\
\hline NAC \& non-DUOS center & 25 & 19 & 15 & 11 & 6 & 5 & 2 & 2 & $47.3(26.9-65.2)$ & 0.355 \\
\hline No NAC \& non-DUOS center & 113 & 77 & 62 & 43 & 33 & 26 & 17 & 11 & $31.8(22.8-41.3)$ & \\
\hline
\end{tabular}


$(p=0.006)$ (Figure 1B). This retained its significance in CT3-4a patients, after dividing the population into patients with organ-confined (cT2) versus extravesical disease (cT3-4a) $(p=0.0002)$ (Figure 2A and Figure 2B). Survival at non-DUOS centers did not significantly differ between patients treated with or without NAC (Figure $1 \mathrm{~B}$, Figure $2 \mathrm{~A}$ and Figure $2 \mathrm{~B}$ ).

After stratifying the population into CT2 and CT3-4a patients, the 5 -year OS in CT2 patients who were treated with NAC and RC did not differ between type of center (54.2\% (95\% Cl: 43.8-63.6) vs. 56.6\% (95\% Cl: 41.4$69.3, p=0.36$ ) (Figure 2A). Patients treated with NAC and RC at DUOS centers had a $6.2 \%$ superior survival compared to RC without NAC at non-DUOS centers ( $p$ $=0.02$ ) (Figure 2A). In CT3-4 patients treated with NAC and RC, the 5-year OS differed 13.8\% (DUOS: $61.1 \%$ (95\% Cl: $50.4-70.2)$ versus non-DUOS: $47.3 \%(95 \% \mathrm{Cl}$ : $26.9-65.2))$, which did not reach statistical significance ( $p=0.26$ ) (Figure 2B). In cT3-4a patients treated with RC and NAC at DUOS centers, the 5 -year OS was $61.1 \%$ (95\% Cl: 50.4 - 70.2) versus 31.8\% (95\% Cl: 22.8-41.3)) for CT3-T4a patients who had undergone RC without NAC at non-DUOS centers $(p<0.001)$ (Figure $2 B)$.

In patients treated at DUOS centers, significantly more $L N s$ were identified $(P<0.0001)$ (Table 1$)$. In a larger percentage of patients at non-DUOS centers, the number of dissected or counted LNs was unavailable of not specified ( $22 \%$ vs. $16 \%, p<0.001)$ as well as lacking documentation about positive $\mathrm{LNs}(12 \%$ vs. $6 \%$ of patients). There was a small, but significant, difference in the presence of positive surgical margins ( $9 \%$ vs. $7 \%$ ) in favor of treatment at DUOS centers $(p=0.02)$.

Univariate Cox regression analysis (Table 2) showed a small positive, but non-significant association of being treated at a DUOS center on OS. The step by step addition of patient characteristics (model 2), NAC (model 3 ), and (post)-operative factors to the Cox-regression multivariable model had little effect on the hazard ratio of being treated at a DUOS center. In the final model, the type of center still had a small non-significant beneficial association with OS. The multivariable Cox-regression (model 4) showed a significant effect for age, the number of identified LNs, the number of positive LNs, and surgical margins status in the total group and both stage groups. In addition, NAC showed only a positive effect ( $p=0.04$, HR: $0.72,95 \% \mathrm{Cl}: 0.53-0.99)$ in the cT34 cohort. Lacking documentation on the number of identified or positive LNs was negatively associated with survival.

\section{Discussion}

Reported disease-free survival and OS for MIBC patients are still fueling debate on factors that are either hypothetically or more likely associated with survival outcome. Discussions about minimum standards of care and centralization of MIBC management are standard components in these discussions. Also variable use of NAC in clinical practice despite level 1 evidence is part of this discussion [17-22]. For the Dutch cancer population, several factors are being registered in the

Table 1: Histopathological characteristics of the radical cystectomy specimen and the 30-day mortality rate (total group).

\begin{tabular}{|c|c|c|c|c|c|c|c|}
\hline & \multicolumn{5}{|c|}{ DUOS center } & \multirow{2}{*}{\multicolumn{2}{|c|}{ Total }} \\
\hline & \multicolumn{2}{|c|}{ No } & \multicolumn{2}{|l|}{ Yes } & \multirow[t]{2}{*}{ P-value } & & \\
\hline & $\mathbf{N}$ & $\%$ & $\mathbf{N}$ & $\%$ & & $\mathbf{N}$ & $\%$ \\
\hline Number of identified LNs & & & & & $<0.0001$ & & \\
\hline Number of dissected/counted LN not documented & 198 & 22 & 412 & 16 & $<0.001$ & 610 & 18 \\
\hline $1-9$ & 277 & 31 & 832 & 32 & & 1109 & 32 \\
\hline$\geq 10$ & 414 & 47 & 1339 & 52 & & 1753 & 50 \\
\hline Number of positive LNs & & & & & $<0.001$ & & \\
\hline No positive LNs & 610 & 69 & 1899 & 74 & & 2509 & 72 \\
\hline $1-4$ & 146 & 16 & 460 & 18 & & 606 & 17 \\
\hline $5-9$ & 15 & 2 & 48 & 2 & & 63 & 2 \\
\hline$\geq 10$ & 9 & 1 & 16 & $<1$ & & 25 & 1 \\
\hline Positive LNs documented, but number unknown & 4 & $<1$ & 10 & $<1$ & & 14 & $<1$ \\
\hline No documentation of positive LNs & 105 & 12 & 150 & 6 & & 255 & 7 \\
\hline Surgical margins of cystectomy & & & & & 0.02 & & \\
\hline negative & 782 & 88 & 2301 & 89 & & 3083 & 89 \\
\hline positive & 80 & 9 & 171 & 7 & & 251 & 7 \\
\hline Unknown & 27 & 3 & 111 & 4 & & 138 & 4 \\
\hline 30-day postoperative mortality & 21 & 2.4 & 56 & 2.2 & 0.90 & 77 & 2 \\
\hline Complete pathological response (ypTONO) after NAC and RC & 23 & 29 & 66 & 27 & 0.70 & 89 & 28 \\
\hline Pathological stage $(\mathrm{pT})$ at $\mathrm{RC}$ & & & & & 0.11 & & \\
\hline pT0 & 37 & 4 & 83 & 3 & & 120 & $3 \%$ \\
\hline pT1 & 27 & 3 & 82 & 3 & & 109 & $3 \%$ \\
\hline pT2 & 352 & 40 & 1025 & 40 & & 1377 & $40 \%$ \\
\hline pT3 & 367 & 41 & 1051 & 41 & & 1418 & $41 \%$ \\
\hline pT4 & 94 & 11 & 264 & 10 & & 358 & $10 \%$ \\
\hline pTX or pT missing & 12 & 1 & 78 & 3 & & 90 & $3 \%$ \\
\hline
\end{tabular}


Table 2: Cox-regression on overall survival.

\begin{tabular}{|c|c|c|c|c|c|c|c|c|c|}
\hline & \multicolumn{3}{|c|}{ All stages } & \multicolumn{3}{|c|}{ cT2 cNo/X } & \multicolumn{3}{|c|}{ cT3-4 cNO/X } \\
\hline & HR & $95 \% \mathrm{Cl}$ & P-value & HR & $95 \% \mathrm{Cl}$ & P-value & HR & $95 \% \mathrm{Cl}$ & P-value \\
\hline \multicolumn{10}{|l|}{ Model ${ }^{*}$} \\
\hline \multicolumn{10}{|l|}{ DUOS Center } \\
\hline No & 1.00 & & & 1.00 & & & 1.00 & & \\
\hline Yes & 0.94 & $(0.84-1.05)$ & 0.28 & 0.93 & $(0.83-1.06)$ & 0.27 & 0.92 & $(0.72-1.19)$ & 0.52 \\
\hline \multicolumn{10}{|l|}{ Model $2^{* *}$} \\
\hline \multicolumn{10}{|l|}{ DUOS Center } \\
\hline No & 1.00 & & & 1.00 & & & 1.00 & & \\
\hline Yes & 0.96 & $(0.86-1.07)$ & 0.44 & 0.96 & $(0.84-1.08)$ & 0.45 & 0.91 & $(0.70-1.18)$ & 0.44 \\
\hline \multicolumn{10}{|l|}{ Model $3^{* * *}$} \\
\hline \multicolumn{10}{|l|}{ DUOS Center } \\
\hline No & 1.00 & & & 1.00 & & & 1.00 & & \\
\hline Yes & 0.96 & $(0.86-1.07)$ & 0.45 & 0.96 & $(0.85-1.08)$ & 0.45 & 0.92 & $(0.72-1.19)$ & 0.53 \\
\hline \multicolumn{10}{|l|}{ Model $4^{* * * *}$} \\
\hline \multicolumn{10}{|l|}{ DUOS Center } \\
\hline No & 1.00 & & & 1.00 & & & 1.00 & & \\
\hline Yes & 0.94 & $(0.84-1.05)$ & 0.27 & 0.93 & $(0.82-1.06)$ & 0.27 & 0.97 & $(0.74-1.26)$ & 0.81 \\
\hline \multicolumn{10}{|l|}{ Neo-adjuvant chemotherapy } \\
\hline No & 1.00 & & & 1.00 & & & 1.00 & & \\
\hline Yes & 0.98 & $(0.81-1.18)$ & 0.80 & 1.05 & $(0.83-1.33)$ & 0.70 & 0.72 & $(0.53-0.99)$ & 0.04 \\
\hline \multicolumn{10}{|l|}{ Differentiation grade } \\
\hline Well or moderately differentiated & 1.00 & & & 1.00 & & & 1.00 & & \\
\hline Poorly differentiated & 1.06 & $(0.86-1.31)$ & 0.61 & 1.03 & $(0.82-1.31)$ & 0.78 & 1.18 & $(0.69-2.03)$ & 0.55 \\
\hline Unknown & 1.11 & $(0.75-1.66)$ & 0.60 & 1.17 & $(0.76-1.81)$ & 0.48 & 0.95 & $(0.34-2.68)$ & 0.92 \\
\hline \multicolumn{10}{|l|}{ Number of identified LNs } \\
\hline $1-9$ & 1.33 & $(1.2-1.48)$ & $<0.0001$ & 1.32 & $(1.17-1.49)$ & $<0.0001$ & 1.47 & $(1.16-1.86)$ & 0.00 \\
\hline$\geq 10$ & 1.00 & & & 1.00 & & & 1.00 & & \\
\hline $\begin{array}{l}\text { Number of LN dissected/counted } \\
\text { not documented }\end{array}$ & 1.04 & $(0.88-1.23)$ & 0.66 & 1.04 & $(0.87-1.26)$ & 0.67 & 1.02 & $(0.68-1.54)$ & 0.91 \\
\hline \multicolumn{10}{|l|}{ Number of positive LNs } \\
\hline No positive LNs & 1.00 & & & 1.00 & & & 1.00 & & \\
\hline $1-4$ & 2.07 & $(1.85-2.31)$ & $<0.0001$ & 2.08 & $(1.83-2.36)$ & $<0.0001$ & 1.87 & $(1.47-2.38)$ & $<0.0001$ \\
\hline $5-9$ & 3.82 & $(2.89-5.06)$ & $<0.0001$ & 4.21 & $(3.02-5.87)$ & $<0.0001$ & 2.80 & $(1.64-4.78)$ & 0.00 \\
\hline$\geq 10$ & 4.06 & $(2.19-7.55)$ & $<0.0001$ & 5.75 & $(2.53-13.09)$ & $<0.0001$ & 2.15 & $(0.77-6.06)$ & 0.15 \\
\hline $\begin{array}{l}\text { Positive LNs, but number } \\
\text { unknown }\end{array}$ & 3.90 & $(2.57-5.93)$ & $<0.0001$ & 3.43 & $(2.06-5.73)$ & $<0.0001$ & 4.80 & $(2.28-10.08)$ & $<0.0001$ \\
\hline \multicolumn{10}{|l|}{ Surgical margins of cystectomy } \\
\hline negative & 1.00 & & & 1.00 & & & 1.00 & & \\
\hline positive & 2.51 & $(2.14-2.94)$ & $<0.0001$ & 2.62 & $(2.16-3.18)$ & $<0.0001$ & 2.19 & $(1.64-2.92)$ & $<0.0001$ \\
\hline Unknown & 2.12 & $(1.7-2.64)$ & $<0.0001$ & 2.16 & $(1.68-2.76)$ & $<0.0001$ & 2.11 & $(1.3-3.43)$ & 0.00 \\
\hline
\end{tabular}

*Model 1: Univariate model on effect of being treated in DUOS center vs. not being treated in a DUOS center; ${ }^{* *}$ Model 2: Multivariable model on effect of being treated in DUOS center vs. not being treated in a DUOS center with correction for patient characteristics (gender, age and period of diagnosis), only the hazard ratio of DUOS center is being showed; *** Model 3: Model $2+$ with correction for receiving neo-adjuvant chemotherapy (yes vs. no), only the hazard ratio of DUOS center is being showed; **** Model 4: Model $3+$ correction for post-operative factors (differentiation grade, number of identified lymph nodes, number of positive lymph nodes, surgical margin of cystectomy.

Netherlands Cancer Registry, which makes it possible to retrospectively look at survival differences in relation to different factors.

When analyzing differences between DUOS and nonDUOS centers, univariate analysis in the present study showed the best outcome for CT2-4a patients treated with NAC and RC at DUOS centers with a 5-year OS of $57 \%$, whereas patients not treated at DUOS centers by $\mathrm{RC}$ without NAC had the worst outcome with a 5-year OS of $46 \%$. In the subgroup of 620 patients with extravesical disease (cT3-T4a), this difference were more profound with a $29 \%$ difference in the 5 -year OS. Such a difference is not likely to be explained completely by the effect of NAC and selection bias. However, we did identify no significant benefit of NAC for patients treated at nonDUOS centers and advantage of NAC was only seen in cT3-4 patients treated at DUOS centers. This retained significance in multivariable analyses in this population (HR 0.72, p = 0.04), emphasizing its importance. Since the proportion of patients receiving NAC did not appear different in our dataset, other factors such as type of 
chemotherapy, number of cycles and dose-adherence may have played a role. Also treatment of frail patients is likely associated with management in high-volume centers.

Furthermore, in the univariate analysis there was a significant difference in the extent of the lymph node dissection (LND) and the frequency of negative surgical margins in favor of DUOS centers. These two factors have previously been reported to influence the prognosis following RC $[14-16,22,23]$. The association between quality of LND and high-volume centers is plausible. Several studies have shown an association between survival outcome and treatment at low- or high volume centers [24-26], all favoring treatment at high volume centers. Whether the difference in numbers of $L N s$ is a consequence of the surgical skills or numeration by the pathologist is probably ambiguous, but Leissner, et al. [14] previously showed in their study that the variance in number of LNs was statistically significantly allocated to the different surgeons and not to the pathologists.

In 2011 a Dutch study on the association between high-volume centers and improved outcomes was published [26]. The authors concluded that an important limit is the substantial difference in defining high- or low-volume centers in the literature. For the Dutch situation, this minimum standard has been up scaled in 2015 from $\geq 10$ RCs annually to an average of $\geq 20$ annually over a period of 3 years [27]. The reason that we have excluded hospitals with $<10$ RCs annually for our analysis is a consequence of the period (2005 2014) from which our data originated.

There are several limitations to our study. One is its retrospective nature. Another is the lack of documented comorbidities, including renal function, lack on detailed information on the NAC schemes that have been applied, as well as protocol dose-adherence because these data are not routinely registered in the NCR. Although the use of NAC is nowadays considered standard treatment in the management of MIBC, due to renal function impairment and other comorbidieties in this generally frail patient population, approximately $50 \%$ of patients do not receive NAC. In our study, at centers where NAC was considered standard therapy in all MIBC, it was found that also in later years the frequency of NAC was limited to around $50 \%$ of patients, presumanbly in the majority of cased due to renal function impairment We found no difference in pathological downstaging between type of center, and the proportion of complete downstaging, which is in accordance with the literature $[20,28,29]$. The slightly larger difference in survival for patients treated with NAC at DUOS centers as compared with literature [18-20] might be a result from bias by selecting patients fit to receive platinum-based chemotherapy, as well as improved NAC regimens (gemcitabin/cisplatin or dose dense MVAC) over the years.

\section{Conclusions}

When comparing centers involved in a multidisciplinary national network (DUOS), we found a statistical significant greater survival benefit by the use of NAC, a significant higher number of lymph nodes identified, and a lower rate of positive surgical margins. There was a non-significant trent towards overall survival benefit.

\section{References}

1. http://www.wcrf.org/int/cancer-facts-figures/data-specificcancers/bladder-cancer-statistics

2. http://www.cijfersoverkanker.nl/nkr/

3. Hermans TJN, Fransen van de Putte EE, Horenblas S, Lemmens V, Aben K, et al. (2016) Perioperative treatment and radical cystectomy for bladder cancer--a population based trend analysis of 10,338 patients in the Netherlands. Eur J Cancer 54: 18-26.

4. Reardon ZD, Patel SG, Zaid HB, Stimson CJ, Resnick MJ, et al. (2015) Trends in the Use of perioperative chemotherapy for localized and locally advanced muscle-invasive bladder cancer: A sign of changing tides. Eur Urol 67: 165-170.

5. Rochon J, du Bois A, Lange T (2014) Mediation analysis of the relationship between institutional research activity and patient survival. BMC Med Res Methodol 22: 1-8.

6. standardisation of multidisciplinary cancer care in the netherlands (2017) soncos standardisation report.

7. Rosenberg JE, Hoffman-Censits J, Powles T, van der Heijden MS, Balar AV, et al. (2016) Atezolizumab in patients with locally advanced and metastatic urothelial carcinoma who have progressed following treatment with platinum-based chemotherapy: a single-arm, multicentre, phase 2 trial. Lancet 387: 1909-1920.

8. Petrylak DP, de Wit R, Chi KN, Drakaki A, Sternberg $\mathrm{CN}$, et al. (2017) Ramucirumab plus docetaxel versus placebo plus docetaxel in patients with locally advanced or metastatic urothelial carcinoma after platinum-based therapy (RANGE): a randomised, double-blind, phase 3 trial. Lancet 390: 2266-2277.

9. Balar AV, Castellano D, O'Donnell PH, Grivas P, Vuky J, et al. (2017) First-line pembrolizumab in cisplatin-ineligible patients with locally advanced and unresectable or metastatic urothelial cancer (KEYNOTE-052): a multicentre, single-arm, phase 2 study. Lancet Oncol 18: 1483-1492.

10. Casparie M, Tiebosch AT, Burger G, Blauwgeers $H$, van de Pol A, et al. (2007) Pathology databanking and biobanking in The Netherlands, a central role for PALGA, the nationwide histopathology and cytopathology data network and archive. Cell Oncol 29: 19-24.

11. Gospodarowicz G, Wittekind C, Sobin L (2009) TNM Atlas. ( $7^{\text {th }}$ edn), Chichester, UK: Hoboken, NJ: Wiley-Blackwell.

12. Percy C, Jack A, Fritz A (2000) International classicification of disease for oncology. ( $3^{\text {rd }}$ edn $)$, World Health Organization, Geneva.

13. Multidisciplinaire Normering Oncologische Zorg in Nederland (2014) Soncos Standardisation Report.

14. Leissner J, Hohenfellner R, Thüroff JW, Wolf HK (2000) Lymphadenectomy in patients with transitional cell carcinoma of the urinary bladder; significance for staging and prognosis. BJU Int 85: 817-823.

15. Koppie TM, Vickers AJ, Vora K, Dalbagni G, Bochner 
BH (2006) Standardization of pelvic lymphadenectomy performed at radical cystectomy: can we establish a minimum number of lymph nodes that should be removed? Cancer 107: 2368-2374.

16. Herr H, Lee C, Chang S, Lerner S, Bladder Cancer Collaborative Group (2004) Standardization of radical cystectomy and pelvic lymph node dissection for bladder cancer: a collaborative group report. J Urol 171: 823-1828.

17. Griffiths G, Hall R, Sylvester R, Raghavan D, Parmar MK (2011) International Phase III trial assessing neoadjuvant cisplatin, methotrexate, and vinblastine chemotherapy for muscle-invasive bladder cancer: long-term results of the BA06 30894 trial. J Clin Oncol 29: 2171-2177.

18. Sherif A, Holmberg L, Rintala E, Mestad O, Nilsson J, et al. (2004) Neoadjuvant cisplatinum based combination chemotherapy in patients with invasive blader cancer: a combined analysis of two Nordic studies. Eur Urol 45: $297-$ 303.

19. Advanced bladder cancer (ABC) meta-analysis collaboration (2005) Neoadjuvant chemotherapy in invasive bladder cancer: update of a systematic review and meta-analysis of individual patient data. Eur Urol 48: 202-206.

20. Grossman HB, Natale RB, Tangen CM, Vogelzang NJ, Trump DL, et al. (2003) Neoadjuvant Chemotherapy plus Cystectomy Compared with Cystectomy Alone for Locally Advanced Bladder Cancer. NEJM 2003: 859-866.

21. International collaboration of trialists on behalf of the Medical Research Council Advanced Bladder Cancer Working Party*, EORTC Genito-Urinary Group, Australian Bladder Cancer Study Group, National Cancer Institute of Canada Clinical Trials Group, Finnbl CUE de TO (CUETO) group (1999) Neoadjuvant cisplatin, methotrexate, and vinblastine chemotherapy for muscle-invasive bladder cancer: a randomised controlled trial. Lancet 354: 533-540.
22. Juergen E. Gschwend, Matthias M. Heck, Jan Lehmann, Herbert Ruebben, Peter Albers, et al. (2016) Limited versus extended pelvic lymphadenectomy in patients with bladder cancer undergoing radical cystectomy: survival results from a prospective, randomized trial (LEA AUO AB 25/02). J Clin Oncol 34: 4503.

23. Abufaraj M, Gust K, Moschini M, Foerster B, Soria F, et al. (2016) Management of muscle invasive, locally advanced and metastatic urothelial carcinoma of the bladder: a literature review with emphasis on the role of surgery. Transl Androl Urol 5: 735-744.

24. Hughes R, Hunt S, Luft $H$ (1987) Effects of surgeon volume and hospital volume on quality of care in hospitals. Med Care 25: 489-503.

25. Halm E, Lee C, Chassin M (2002) Is volume related to outcome in health care? A systematic review and methodologic critique of the literature. Ann Intern Med 137: 511-520.

26. Goossens-Laan CA, Gooiker GA, van Gijn W, Post PN, Bosch JL, et al. (2011) A systematic review and metaanalysis of the relationship between hospital/surgeon volume and outcome for radical cystectomy: an update for the ongoing debate. Eur Urol 59: 775-783.

27. Multidisciplinaire normering oncologische zorg in nederland (2015) soncos report.

28. Rosenblatt $R$, Sherif $A$, Rintala $E$, Wahlqvist $R$, Ullén $A$, et al. (2012) Pathologic downstaging is a surrogate marker for efficacy and increased survival following neoadjuvant chemotherapy and radical cystectomy for muscle-invasive urothelial bladder cancer. Eur Urol 61: 1229-1238.

29. Hermans TJ, Fransen van de Putte EE, Horenblas S, Meijer RP, Boormans JL, et al. (2016) Pathological downstaging and survival after induction chemotherapy and radical cystectomy for clinically node-positive bladder cancerResults of a nationwide population-based study. Eur $\mathrm{J}$ Cancer 69: 1-8. 
Table S1: Patient and tumor characteristics at moment of diagnosis.

\begin{tabular}{|c|c|c|c|c|c|c|c|}
\hline & \multicolumn{5}{|c|}{ DUOS center } & \multirow{2}{*}{\multicolumn{2}{|c|}{ Total }} \\
\hline & \multicolumn{2}{|c|}{ No } & \multicolumn{2}{|l|}{ Yes } & \multirow[t]{2}{*}{ P-value } & & \\
\hline & $\mathbf{N}$ & $\%$ & $\mathbf{N}$ & $\%$ & & $\mathbf{N}$ & $\%$ \\
\hline Age & & & & & 0.053 & & \\
\hline$<60$ years & 168 & 19 & 556 & 22 & & 724 & 21 \\
\hline $60-69$ years & 311 & 35 & 940 & 36 & & 1251 & 36 \\
\hline 70-79 years & 331 & 37 & 915 & 35 & & 1246 & 36 \\
\hline $80+$ years & 79 & 9 & 172 & 7 & & 251 & 7 \\
\hline Gender & & & & & 0.14 & & \\
\hline Male & 687 & 77 & 1933 & 75 & & 2620 & 75 \\
\hline Female & 202 & 23 & 650 & 25 & & 852 & 25 \\
\hline Period of diagnosis & & & & & 0.32 & & \\
\hline $2005-2007$ & 191 & 21 & 610 & 24 & & 801 & 23 \\
\hline $2008-2010$ & 257 & 29 & 759 & 29 & & 1016 & 29 \\
\hline 2011-2014 & 441 & 50 & 1214 & 47 & & 1655 & 48 \\
\hline cT-stage & & & & & 0.10 & & \\
\hline cT2 & 751 & 84 & 2101 & 81 & & 2852 & 82 \\
\hline cT3 & 100 & 11 & 355 & 14 & & 455 & 13 \\
\hline cT4a & 38 & 4 & 127 & 5 & & 165 & 5 \\
\hline cN-stage & & & & & 0.93 & & \\
\hline cNO & 787 & 89 & 2284 & 88 & & 3071 & 88 \\
\hline cNX & 102 & 11 & 299 & 12 & & 401 & 12 \\
\hline Tumor differentiation grade & & & & & $<0.01$ & & \\
\hline Well or moderately differentiated & 70 & 8 & 129 & 5 & & 199 & 6 \\
\hline Poorly differentiated & 801 & 90 & 2399 & 93 & & 3200 & 92 \\
\hline Unknown & 18 & 2 & 55 & 2 & & 73 & 2 \\
\hline \multicolumn{8}{|l|}{ Neo-adjuvant chemotherapy } \\
\hline No & 811 & 91 & 2341 & 91 & 0.60 & 3152 & 91 \\
\hline Yes & 78 & 9 & 242 & 9 & & 320 & 9 \\
\hline Total & 889 & 100 & 2583 & 100 & & 3472 & 100 \\
\hline
\end{tabular}

2583

3472 